\title{
Editorial
}

\section{Reporting Science}

The way the media report on science has recently become the subject of considerable attention, and brought an equal measure of handwringing. Representations of science in the news influence how people regard scientific consensus, shape perceptions of ongoing controversies, and thereby mediate the cultural authority science wields. In the midst of a pandemic, when various sorts of scientific authority are vying to shape urgent policy measures, the importance of that mediating role is thrown into particularly sharp relief.

But historical perspectives on that process are no less important, and an article in this issue gives us just such perspective. Victória Flório and Olival Freire Júnior examine astronomy's "Great Debate" of the 1920s, which pitted Harlow Shapley against Heber Doust Curtis, who disagreed how to interpret astronomical evidence of spiral nebulae. Shapley defended the interpretation that they resided within the Milky Way, whereas Curtis interpreted them as distant galaxies in their own right, implying a much larger universe. Flório and Freire Júnior reveal the role of the press in framing what would become the myth of the Great Debate.

In fact, as Flório and Freire Júnior show, the way that Shapely and Curtis-who were both reputation-conscious-engaged each other's views was courteous and circumspect, and although they disagreed, the engagement was far from the sort of contest the word "debate" brings to mind. But for the newspaper media of the day, the narrative of a heavyweight bout between the leaders of two major observatories was too enticing to pass up, and so early accounts of the encounter presented it as much more adversarial than it likely was, contributing to forging the myth of the Great Debate.

Both the similarities to and the differences with our current moment are instructive. Then, as now, controversy is compelling. Disagreement, discord, and dissent move paper-or drive clicks. Much attention has been paid to the way that the fairness doctrine-the principle that media outlets should provide equal time to both sides of an issue-has distorted public opinion around issues that in fact enjoy extremely strong scientific consensus. A related issue, though, might be called conflict amplification. The fairness doctrine heightens a sense of disagreement in times of scientific consensus, whereas conflict amplification-the assumption that scientific differences reflect substantial, sharp contest-heightens the impression of discord in times of scientific uncertainty. Both have the effect of depicting a scientific community riven by disagreement and strife. 
Disagreement is inevitable during periods when scientific consensus is still taking shape, but, as we learn from the case of Shapely and Curtis, it is easy to oversell the oppositional nature of that disagreement, leading to a widespread impression that science proceeds largely through Darwinian competition held within the ecology of ideas. Still, scientific debate is rarely so squarely oppositional, and one worry is that the picture of scientific practice that emerges as a consequence of conflict amplification makes the fallacy of equal validity promulgated by the fairness doctrine all the more potent.

At the same time, we see some historically distinct features within the story of the Shapely-Curtis encounter. The sort of local print newspapers that did so much of the reporting on the Great Debate would now be unlikely to dispatch a reporter to cover a scientific event, and many more people now get their news from online sources. Flório and Freire Júnior describe the power news reporters wielded to craft a popular impression of an event witnessed by a relatively small number of people. It is an important reminder of how much that has changed. A myth that takes hold on the strength of news reporting and second-hand accounts is quite different from the battery of reactions to events that are live-streamed.

However, even if anyone with an internet connection has access to the content of scientific discussions, they will still be apt to interpret them against the background of a certain understanding of how science operates. Depictions of scientific disagreement in popular media are therefore an issue of ongoing concern, and especially so when we take into account the fact that current depictions of scientific controversy often have to do with scientific practices that are deeply enmeshed with ongoing political disputes. Conflict narratives might be good clickbait, but to the extent that they misrepresent the nature of scientific disagreement, they have the potential to do active harm.

Robert P. Crease

Joseph D. Martin

Richard Staley

Publisher's Note Springer Nature remains neutral with regard to jurisdictional claims in published maps and institutional affiliations. 